REVIEW

\title{
Healthcare reforms: implications for the education and training of acute and critical care nurses
}

S Glen

Postgrad Med J 2004;80:706-710. doi: 10.1136/pgmj.2003.009456

This paper offers a wide ranging analysis of the drivers that resulted in scrutiny of medical, nursing, and healthcare professional roles. It suggests that what is needed is a coherent vision of the future shape of the health workforce. This requires moving beyond the presumption that reforming working practices primarily involves "delegating doctors" responsibilities to nurses. The paper argues that it is self evident that the implications of changes in healthcare roles and the ability of existing professionals to function effectively in the future will require education, training, and human resource investment supportive of the changes. It suggests a clear definition of competence and a national standard to practice is essential for nurses working in acute and acute critical settings. There should therefore be a correlation between levels of practice, levels of education, and remuneration. Furthermore, education programmes for senior nurses should sit coherently alongside the education programmes required by Modernising Medical Careers. Finally, the realisation of the government's service and modernisation agenda will require a culture change within higher education institutions, postgraduate deaneries, professional organisations, workforce development confederations, and NHS trusts.

Correspondence to: Professor Sally Glen, St Bartholomew School of Nursing and Midwifery, 20 Bartholomew Close, London ECIA 7QN; s.glen@city.ac.uk

Submitted

5 September 2003

Accepted

23 September 2003
A cute and critical care delivery has been under close scrutiny. Comprehensive Critical Care challenged and redirected the way in which critical care services should be managed and delivered. ${ }^{1}$ The report involved a conceptual shift of delivering a service to patients based on need rather than locality-the so-called "critical care without walls" approach. ${ }^{12}$ The patient is thus firmly placed to the forefront of service provision, which has implications for the training and education of all healthcare professions.

A dramatic shift in the scale of skill mix changes will also need to take place if the government's vision for the NHS is to be realised. The emergence of expanded and extended clinical roles, and indeed new clinical roles across the healthcare professions, has provided each of the health professions with opportunities to review it's contribution to healthcare and to the multiprofessional team it works in to deliver health services. The scrutiny is a necessary aspect of modernising healthcare. It is inconceivable that the increased demand for acute and critical healthcare can be met using the current skill mix.

This paper identifies the driving forces, outlines the interprofessional education and training implications for all healthcare professions, alongside the specific uniprofessional education and training implications for nursing. Broad conclusions are drawn for the future.

\section{POLICY DRIVERS}

It is tempting for healthcare professionals to believe that the proliferation of new clinical roles for the healthcare professions are professionally driven. However, the most powerful drivers for change have come from external policy initiatives. These include: firstly the impact of NHS reforms on the way in which services are delivered. ${ }^{3}$ Secondly, the need to find more efficient and cost effective means of providing services-the near universal drive for cost containment in healthcare by means of rational, evidence based intervention. Thirdly, technological developments which allow nurses and therapists to carry out many procedures which in the past would have been undertaken by a doctor. Fourthly, government initiatives such as moves to reduce waiting lists, national service frameworks, health improvement plans and the hours of work of junior doctors, which encourage managers to think creatively about the composition of clinical teams and the allocation of work. Of specific relevance within the context of this paper Comprehensive Critical Care ${ }^{1}$ challenged and redirected the way in which critical care services should be managed and delivered and reclassified acute and critically ill patients into four levels of care as outlined in table 1 .

This classification is potentially a tool useful not only to nursing but to all members of the interdisciplinary team and supports the notion of interdisciplinary post-qualifying education. ${ }^{4-6}$

A defining moment in creating a focus for radical changes in the NHS has also been the Bristol Inquiry. ${ }^{7}$ The findings of the Inquiry have provided a strong lever for the modernisation of the NHS. The Inquiry brought into stark relief the consequences of professional groups socialised into behaviour patterns and working relationships that maintained a pervasive order based on a medical hegemony. The process of socialisation had created a social order of professions which itself became resistant to questioning and change. A diversity of patient and interdisciplinary perspectives can often open up new possibilities for change. However, the maintenance of the status quo through persistent 


\section{Table 1 Classification of patients}

Level 0 Patients whose needs can be met through normal ward care in an acute hospital

Level 1 Patients at risk of their condition deteriorating, or those recently relocated from higher levels of care whose needs can be met on an acute ward with additional advice and support from the critical care team

Level 2 Patients requiring more detailed observation or intervention including support for a single failing organ system or postoperative care and those "stepping down" from higher levels of care

Level 3 Patients requiring advanced respiratory support alone or basic respiratory support together with support of at least two organ systems. This level includes all complex patients requiring support for multiorgan failure

social norms and values often acts to nullify the sought after advantages of diversity.

The above drivers have resulted in scrutiny of medical, nursing, and healthcare professional roles and a recommended reallocation of tasks between doctors, nurses, healthcare professionals, and untrained support staff. It is self evident that no profession can be viewed in isolation: each has a territory of practice that interconnects and often overlaps with that of other professions, managers, and nonprofessionals. The codification of and access to knowledge and the understanding of procedures has gradually opened up the provision to other professions and service providers. As such the division of labour in health could be seen as in a constant state of flux. Thus from the 1970s onwards nurses have been advancing new types of initiatives covering many innovations in various settings, such as prescribing, clinical specialist practice, nurse consultations in primary healthcare, community empowerment, and projects with socially excluded groups. ${ }^{8}$

Senior nursing roles such as clinical nurse specialist, nurse practitioner roles are thus pioneering roles and some have succeeded in demonstrating the skill and availability of nurses to those who may have previously been unsupportive of nurse practicing in a clinically autonomous fashion. The experiences of postholders and the longer term sustainability of these roles will also help identify more precisely the successful models for new advanced clinical role development in the future. A major disadvantage seems to be that the resulting mix of roles are difficult to handle when considering the crucial questions of defining, regulating, and developing roles in the future. For example, many of the resulting posts were bestowed with advanced practitioner specialist titles, regardless of role type or function. Funding for new nursing roles was also often based on short term project grants in response to policy changes or acute need, and consequently posts were usually developed at short notice. This rendered many of the posts relatively insecure, not amenable to longer term development or substantial educational preparation for prospective postholders.

In a classic illustration of how the leverage for major change can come from unexpected quarters, the reduction in junior doctors' hours opened the door to a dramatic and largely unexpected shift in professional relations. In 1996 the government decided to formalise and encourage arrangements often already in place that empowered senior clinical nurses to fill the medical gaps. They were carrying out many tasks that would have been done by the absent junior doctors and were traditionally regarded as medicine's domain. Funds were made available to regions to train nurses in these skills and domains, developing what was to become the first wave of nurse consultants after the role was announced by the Prime Minister at a nursing awards dinner in 1998.

In conclusion to this section, the status quo is rarely identified as an option for the future. ${ }^{9}$ External factors will continue to have an impact on the practice of all professionals in the NHS. In particular, they have major implications for the position of medicine within the healthcare system and the scope of practice within nursing and the healthcare professions. Yet many of the practices in healthcare are steeped in the vestiges of the last century. The considerable complexity of modernising the workforce is coupled with a backdrop of professions and organisations that often seek to defend themselves against change. ${ }^{10}$ The changes and flexibilities sought from the workforce raise fundamental questions about how far reformers are willing to go in challenging the existing medical hegemony. ${ }^{11}$ What is required is a coherent vision for the future.

\section{A COHERENT VISION FOR THE FUTURE}

Professional organisations, trade unions, and government all agree that further changes to working practices will be required in the years ahead. Yet there is little agreement about what the overall shape of the future health workforce should look like. There has been a tendency to presume that reforming working practices primarily involves "delegating" doctors' responsibilities to nurses. New roles and responsibilities for other members of the health team must also be explored.

Healthcare teams in the future are also likely to comprise a greater variety of skill levels. The development of foundation degrees, initiated by the Department for Education and Skills, for example, will see the emergence of an "intermediate professional" in health and social care. Kendall and Lissaur recommend developing new types of staff who work across traditional professional boundaries, including healthcare practitioners to improve the coordination of care and rehabilitation workers. ${ }^{12}$ Kendall and Lissaur's report The Future Health Worker also suggests changing the focus of workforce planning from only delivering more of the same (that is, more doctors and nurses) to producing more and different types of staff who work in new ways.

The British Medical Association (BMA) report is the most recent illustration of a professional group recognising the very significant workforce challenge that the service now faces in health (and social care). ${ }^{9}$ The BMA has called for a hugely expanded role for nurses. It suggests that clinical nurse specialists will coordinate the movement of patients across the system. The BMA does not, however, envisage non-professionally qualified workers taking on more responsibility as nurses' roles expand, something the Wanless report regards as critical if nurses are to help reduce workloads. ${ }^{3}$ An extra 70000 healthcare assistants (in addition to the projected increase in demand of 74000 ) may be needed if nurses are to take on substantially enhanced roles in the future. ${ }^{13}$ Thus, while initiatives which seek to reduce doctors' workloads by expanding nurses roles can help to improve both doctors working lives and the quality of patient care (for example by reducing waiting times), if nurses are also in short supply and become overburdened, the implications for nurses and patients are less clear.

The Royal College of Physicians has put forward a somewhat different solution. ${ }^{14}$ It suggests that the problems being faced by physicians are unlikely to be solved by training existing healthcare professions to take over some of the duties of medical staff. It instead proposes the development of a new type of healthcare practitioner-the physicians' assistant: a semiautonomous professional who carries out similar tasks to physicians including examinations, diagnosis, treatment (including referral), and prescribing. The Royal 
College of Physicians suggests the BMA's model is neither possible (due to the shortage of properly training nurses), nor desirable, since it would take nurses away from other important clinical areas and fail to deliver cost effective care.

When Watson et al reviewed the Anglo-American literature on "mid-level practitioners" in the early $1990 \mathrm{~s},{ }^{15}$ it was still unclear whether the future lay with such nurse practitioners or with a new licensed profession of physicians' assistants. The response of the profession was mixed. A survey of nurses working in South East Thames Regional Health Authority undertaken in the context of the initiative to reduce the working hours of junior doctors, suggested that grass roots nurses favoured holistic roles-such as specialist accident and emergency or outpatients' practitioner-but were resistant to general role extension. The nurses' responses indicated that the latter would result in work overload and lead to further fragmentation of care, whereas the former allowed nurses the scope to combine medically derived tasks with a patient centred approach. ${ }^{16}$

By the end of the decade, there no longer seemed to be any controversy over the idea that nurses would play a major part in first patient contracts, make triage decisions and administer a wide range of minor treatments, prescribing drugs, and carrying out a number of surgical procedures. ${ }^{17}$ Medical support would not necessarily be on site, but may be provided by telephone or video links. However, managers and policy makers mostly gave only lukewarm support until pragmatism forced them to adopt "new" solutions. ${ }^{8}$ At local level some doctors actively opposed them, as in the notorious closure of the Oxford Nursing Development Unit. This developed an early pioneering model of nurse-led intermediate care for patients who no longer needed intensive attention from medicine. Evaluation including a randomised controlled trail showed better outcomes for patients including fewer deaths and greater independence on discharge, but research evidence could not over-ride the opposition of some medical consultants who regarded it as an affront to their power. ${ }^{18}$

Nurses are not the only group to experience this change: pharmacists are seeing a similar development of their role in the community, for example, and as previously suggested, recent UK government documents signal further moves to dismantle traditional lines of demarcation. ${ }^{356}$ However, as nurses absorb the performance of technical tasks into their routine practice, will they have to delegate more of their caring activities to healthcare assistants? ${ }^{19}$

\section{TOWARDS AN EDUCATIONAL FRAMEWORK}

Successive governments have focused more on changing the structures of the NHS than on reforming the working practices, cultures, and attitudes of the staff within in. Yet these issues are critical in determining the quality of care patients receive. $^{12}$ It is therefore self evident that the implications of changes in healthcare roles and the ability of existing professionals to function effectively in the future will require education, training, and human resource investment supportive of the changes. Inherent within all educational programmes should be an emphasis on facilitating learning (rather than just traditional education, teaching, and training) so that healthcare professionals are equipped to carry on learning as part of their future development and lifelong learning programmes. In nursing a whole system approach is required.

\section{Nursing: a whole system approach}

Pre-qualifying and post-qualifying nursing education, development, and training must become fully integrated with the practice of nursing. This will require infrastructure development between service and education. Nurses are increasingly trained by specialist educators whose sense of their mandate is rather different from those who are involved in the everyday delivery of the service. ${ }^{19}$ Nurse educators occupy a structural location where they do not have to deal with the tensions, which result between investment in the technical and the holistic. The result, however, is that nurses are trained to do a job that did not exist in the past, does not exist in the present, and may never exist in the future.

\section{Pre-qualifying nursing education}

More technical skills need to be included in the prequalifying nursing programme in order to meet the greater acuity needs of patients. The acute and critical care component within these programmes currently remains ambiguous. The former English National Board for Nursing, Midwifery and Health Visiting, in line with a view of a prequalifying nursing education report entitled Fitness for Practice, ${ }^{20}$ identified a need for core professional nursing competencies; each educational institution is currently forced to define their own. This can lead to variations in expected practice. A clear definition of competency and a national standard of the knowledge required to practice is essential. ${ }^{21}$

\section{Post-qualifying nursing education}

Integration of core competencies within post-qualifying acute and critical care programmes has become a priority. The diversity of different arrangements (for example, part time attendance, distance learning, and learning outcomes) has caused the emergence of "postcode competencies" - a term used to describe the variations in competence related to where (that is, the postcode) the staff nurse undertook their degree or diploma in acute or critical care nursing. There is therefore inconsistency in the knowledge and skills that staff nurses can be exposed to by the end of the educational programmes. ${ }^{22}$

The implications of The Nursing Contribution to the Provision of Comprehensive Critical Care for Adults for the role of the "critical care nurse" are the transferability of skills and matching the patient transition through the critical care service. ${ }^{5}$ The literature contains examples of the development of competency frameworks that have been designed for use with all levels of patients as defined by "Comprehensive Critical Care $^{\prime \prime 5}$ and could be used in all geographical locations including general ward areas, high dependency and intensive care units. ${ }^{23-28}$ Utilising a competency based framework performance criteria can be identified for patients at levels $0,1,2$, and 3 (table 1).

In the past pay and career progression in nursing has been weighted towards the managerial concept of responsibility for a number of people and a budget. The Agenda for Change explores the NHS pay system signalling the intention of the government to encourage staff to be more flexible, to be rewarded for responsibility, and to prove competence and satisfactory performance levels. ${ }^{29}$ There will be clear national pay thresholds for key career changes linked by competencies and which leads to the need for educational development. Education pathways in acute and critical care should therefore be designed to dovetail with the skills and careers escalators to make it easy for staff to reach their full potential. For example, to assist advanced practitioners who aspire to be consultant practitioners. The nurse consultant role as described by the Department of Health reflects a fundamental change in the view of nursing's position within the healthcare system in the UK. ${ }^{30}$ The nurse consultant role is a response to both the increased public demand for a healthcare system focused on their individual needs and a willingness at a strategic level to breakdown previous professional barriers and encourage new ways of working. ${ }^{3}$ As previously suggested, a dramatic shift in the scale of skill mix changes will need to take place if the government's vision for the NHS is to be realised. Key to this vision are the 
principles of learning together and developing new educational pathways and routes for new role reconfiguration.

\section{INTERPROFESSIONAL LEARNING}

The pace of change in healthcare policy shows no sign of diminishing under the Labour government. A significant change is that education and training are acknowledged as essential factors in enabling the achievement of the government's aims for health and social care. This is demonstrated in the many policies that refer to the importance of education. ${ }^{3-6}$ There are three overarching messages within all of these policies which are that, if the NHS modernisation agenda is to be a success, there is a need for better interprofessional team working, improved recruitment and retention of staff, and a workforce that has the appropriate knowledge and skills and is "fit for purpose".

The Bristol Inquiry identified a range of areas that it viewed as crucially important to the care of patients, ${ }^{7}$ which should be reflected as a basis for common learning and thereby broadening the notion of competence. The six key areas included: skills in communicating with patients and colleagues; education about the principles and organisation of the NHS; how care is managed and the skills required for management; the development of teamwork; shared learning across professional boundaries; clinical audit and reflective practice and leadership.

Between 2000 and 2002 the Department of Health's policy emphasis was on developing interprofessional education within pre-qualifying education. Pragmatic development towards more interprofessional learning is currently taking priority which includes aims for "threads" of interprofessional learning in all programmes. More recently the Department of Health has focused on developing a shared framework for health professional learning beyond registration and linking education to service delivery plans. ${ }^{6}$ In the future, education programmes for senior nurses should sit coherently alongside education programmes required by Modernising Medical Careers $^{31}$ and the future preparation of acute and critical care healthcare practitioners takes place in the same world of acute and critical care. With this comes the potential for recognition of the respective jurisdictions of practice, developing flexibility, open mindedness, reducing prejudice and stereotyping, building mutual respect, and understanding of the common world of patient centred care.

\section{CONCLUSION}

With health a daily concern, healthcare high on the political agenda, and the quality of care in the NHS perceived to be inadequate on many counts, hitherto unquestioned assumptions and practices are being scrutinised and challenged. There is also a current policy emphasis on developing postqualification outcomes, which reflect and support service and the workforce modernisation agenda. ${ }^{36}$ Fitness for purpose for the next generation of health professionals is being conceptualised in policy documents in terms of shared core knowledge and competencies, team working, flexibility, and potential skills transferability. This suggests that a shift in culture towards a new professionalism, based on shared practice, knowledge and values is required, in contrast to the traditional model of professionalism which emphasises the differences between professions through separate systems of regulation, pay, and education. ${ }^{8}$ The realisation of the governments' service and modernisation agenda will thus require a cultural change within higher education institutions, postgraduate deaneries, professional organisations, workforce development confederations, and NHS trusts. In addition, acute and critical care delivery has been under close scrutiny and the patient is now firmly placed at the forefront of service provision.
Pre-qualifying and post-qualifying education should be conceptualised as contiguous. The critical care component of pre-qualifying nursing programmes currently remains ambiguous and needs reviewing and outcomes related to acute and critical care made more explicit. At the post-qualifying level each educational institution is currently forced to define their own competencies, which can lead to variation in expected practice. A clear definition of competency and a national standard of knowledge required to practice is essential. Educational programmes for senior nurses should sit coherently alongside the educational programmes required by Modernising Medical Careers. ${ }^{31}$ Such an interprofessional educational programme might constitute core interprofessional competencies and core uniprofessional competencies in line with the Bristol Inquiry report ${ }^{7}$ and explicitly linking levels of practice, levels of education, and remuneration. ${ }^{29}$

Whether it is helpful to put so much emphasis upon common studies is another matter. Persuasive arguments have been put for adjusting or redressing the balance between common and specialist studies. ${ }^{32}$ The danger lies in taking the argument to extremes, thereby detracting from the distinctive contribution that each profession makes to service delivery. Over emphasis upon "common" or "core" studies also runs counter to strongly held beliefs in interprofessional education. One might argue that patients and clients receive the highest standards of healthcare in specialist referral centres. A policy focus on developing "common" or "core" studies might divert resources from developing specialist knowledge and skills leading, in the longer term, to a decline in standards of care at specialist centres but an overall improvement in standards across healthcare. What is certain is that no profession can be viewed in isolation and the division of labour in acute and critical care is in a constant state of flux.

\section{REFERENCES}

1 Department of Health. Comprehensive critical care: a review of adult critical care services. London: Stationery Office, 2000.

2 Department of Health. Guidelines on admission and discharge from intensive care and high dependency units. London: Stationery Office, 1996.

3 Department of Health. The NHS plan: a plan for reform. London: Stationery Office, 2000.

4 Department of Health. A health service of all the talents: developing the NHS workforce, consultation document. London: DoH, 2000.

5 Department of Health. Working together-learning together: a framework for lifelong learning for the NHS. London: DoH, 2001.

6 Department of Health. Learning for delivery: making a connection between post qualification learning and continuing professional development and service planning [draft]. London: DoH, 2003.

7 The Bristol Royal Infirmary Inquiry. Learning from Bristol: the report of the public inquiry into children's heart surgery at the Bristol Infirmary 1984-1993. London: Stationery Office, 2003

8 Salvage J. Rethinking professionalism: the first step for patient focused care? Available at: www.ippr.org. London: Institute for Public Policy Research, 2002

9 British Medical Association. Health policy and economic research unit discussion. London: The Future Healthcare Workforce, BMA, 2002:9

10 Humphris D, Masterson A. New clinical roles: a guide for healthcare professions. London: Harcourt Brace, 2000.

11 Cameron A. New role developments in context in developing new clinical roles: a guide for health professionals, In: Humphris D, Masterson A, eds. London: Churchill Livingstone, 2000:7-24.

12 Kendall L, Lissaur R. The future health worker. London: Institute for Public Policy Research, 2003.

13 Wanless D. Securing our future health: taking a long term view. Final report. Stationery Office, 2002

14 Royal College of Physicians. Skill mix and the hospital doctor: new roles for the health care workforce. London: RCP, 2001

15 Watson P, Hendrey N, Dingwell R, et al. The mid-level practitioner: a review of the literature on nurse practitioner and physician assistant programmes. Trent Institute of Health Services, research discussion paper 96/02. Sheffield: Trent Institute for Health Services Research, 1996.

16 Allen D, Hughes D. Expanded nursing roles and the hospital division of labour: the views of nurses and junior doctors: barriers to change or jurisdictional claims-making? Nursing and the division of labour in healthcare. Basingstoke: Macmillan, 2002.

17 Allen D. The changing shape of nursing practice: the role of hospital nurses. London: Routledge, 2001 
18 Salvage J. The new nursing: empowering patients or empowering nurses? In Robinson J, Grey A, Elham R, eds. Policy issues in nursing. Buckingham: Open University Press, 1992

19 Dingwell $\mathbf{R}$, Allen $\mathrm{D}$. The implications of healthcare reforms for the profession of nursing. Nursing Inquiry $2001 ; 8(2): 64-74$.

20 United Kingdom Central Council for Nursing, Midwifery and Health Visiting Fitness for practice. London: UKCC, 1999.

21 Bradshaw A. Defining "competence" in nursing (part II): an analytical review. Journal of Clinical Nursing 1998;7:103-111.

22 Scholes J, Endacott R, Chellel A. Diversity and complexity: a documentary analysis of critical care nursing education. London: English National Board for Nursing, Midwifery and Health Visiting, 1999

23 Fitch M, Eifert C, Mathewman J, et al. Identifying competencies essential for critical care nursing, a Canadian perspective. Journal of The Canadian Association of Critical Care Nurses 1996:7:11-19.

24 Scribante J, Muller ME, Lipman J. A guideline for competency of the critical care nurse. Am J Crit Care 1996;5:217-26.
25 Underwood M, Robertson S, Clarke R. The emergence of competency standards for specialist critical care nurses. Australian Critical Care 1996;9(2):69-71.

26 McKinley S. Critical care education is given a redesign. Nursing Times $2001 ; 97(27): 34-5$

27 Jones M. Critical care competencies. Nursing in Critical Care 2002; 7(3):111-20

28 Bench S, Crowe D, Day T, et al. Critical care competencies. Intensive and Critical Care Nursing 2003;19:136-42.

29 National Health Service Executive. Agenda for change: modernising the NHS pay system. London: HMSO, 1999.

30 National Health Service Executive. Nurse, midwife and health visitor consultants: establishing new posts and making appointments [appended with the UKCC higher level of practice pilot standards]. Health service circular 217. Leeds: NHS Executive, 1999.

31 Department of Health. Modernising medical careers. London: DoH, 2002.

32 Tope R. Integrated interdisciplinary learning between the health and social care professions: a feasibility study. Avebury: Aldershot, 1996.

\section{$\mathrm{ECHO}$}

\section{Videos are useful for training postgraduates in necropsy}

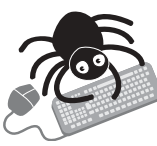

Please visit the Postgraduate Medical

Journal website [www. postgradmed com] for a link to the full text of this article. ideos of necroscopic methods are a valuable teaching aid for postgraduate histopathology students, according to the first study to explore their usefulness. Almost all of 38 senior house officer ( $\mathrm{SHO}$ ) and special registrar delegates at a short course on necropsy reckoned that four structured, scripted necropsy training videos that they were shown enhanced their learning and complemented a practical necropsy demonstration they saw beforehand. Four fifths thought it was difficult to learn as much without the videos, though the SHOs seemed to value them most.

The videos were best for showing specialist methods not normally encountereddissection of the spinal cord, middle ear, and eyes-and were seen as a valuable departmental resource; versatile, permitting learning to suit the individual; and useful for revision. Most delegates found them enjoyable and interesting. Main drawbacks were some repetition - at the expense of detail in general dissection methods—and lack of interactivity; more on specialist methods would have been appreciated.

All delegates who viewed the videos gave their opinions in a short questionnaire. The videos-possibly unique world wide-covered health and safety, evisceration and reconstruction, hospital necropsies, and axial and specialist methods. They were made to be seen individually or as a series by Sheffield University, UK, and formed part of its short course on necropsy in 2001.

Mortuary based training has declined, but the value of alternative teaching aids based on video and computer based technology has until now been assessed only for undergraduates.

\ Burton JL, et al. Journal of Clinical Pathology 2004;57:877-881. 